\title{
Diversity-oriented synthesis catalyzed by DAST - preparation of new antitumor ecdysteroid derivatives
}

\author{
Máté Vágvölgyi 1,a, Endre Kocsis 1,a, Márta Nové ${ }^{2}$, Gabriella Spengler ${ }^{2}$, Zoltán Kele ${ }^{3}$, Róbert Berkecz ${ }^{4}$, Tamás \\ Gáti 5 , Gábor Tóth 6,*, and Attila Hunyadi 1,7,*
}

1 Institute of Pharmacognosy, Interdisciplinary Centre of Excellence, University of Szeged, H-6720 Szeged, Hungary; vagvolgyi.mate@pharmacognosy.hu; endrukocsis2@gmail.com

2 Department of Medical Microbiology and Immunobiology, University of Szeged, H-6720 Szeged, Hungary; nove.marta@gmail.com; spengler.gabriella@med.u-szeged.hu

3 Department of Medical Chemistry, University of Szeged, H-6720, Szeged, Hungary; kele.zoltan@med.uszeged.hu

4 Institute of Pharmaceutical Analysis, University of Szeged, H- 6720 Szeged, Hungary; berkecz.robert@szte.hu

5 Servier Research Institute of Medicinal Chemistry (SRIMC), H-1031 Budapest, Hungary; tamas.gati@hu.netgrs.com

6 Department of Inorganic and Analytical Chemistry, NMR Group, Budapest University of Technology and Economics, H-1111 Budapest, Hungary

7 Interdisciplinary Centre of Natural Products, University of Szeged, H-6720 Szeged, Hungary

a shared first authorship by M.V. and E.K.

* Correspondence: hunyadi.a@pharmacognosy.hu (A.H.); and drtothgabor@t-online.hu (G.T.)

\begin{abstract}
Fluorine represents a privileged building block in pharmaceutical chemistry. Diethylaminosulfur-trifluoride (DAST) is a reagent commonly used for replacement of alcoholic hydroxyl groups with fluorine and is also known to catalyze water elimination and cyclic Beckmann-rearrangement type reactions. In this work we aimed to use DAST for diversity-oriented semisynthetic transformation of natural products bearing multiple hydroxyl groups to prepare new bioactive compounds. Four ecdysteroids, including a new constituent of Cyanotis arachnoidea, were selected as starting materials for DAST-catalyzed transformations. The newly prepared compounds represented combinations of various structural changes DAST was known to catalyze, and a unique cyclopropane ring closure that was found for the first time. Several compounds demonstrated in vitro antitumor properties. A new $17-\mathrm{N}$-acetylecdysteroid (13) exerted potent antiproliferative activity and no cytotoxicity on drug susceptible and multi-drug resistant mouse T-cell lymphoma cells. Further, compound $\mathbf{1 3}$ acted in significant synergism with doxorubicin without detectable direct ABCB1 inhibition. Our results demonstrate that DAST is a versatile tool for diversity-oriented synthesis to expand chemical space towards new bioactive compounds.
\end{abstract}

Keywords: DAST; semi-synthesis; fluorination; Beckmann-rearrangement; cyclopropane; natural product; ecdysteroid; NMR; structure elucidation; anticancer

\section{Introduction}

Due to its small size and high electronegativity, fluorine has become a building block of major importance for medicinal chemistry [1]. Fluorine may serve as a bioisostere and functional mimetic of a wide range of functional groups, while its unique properties confer fluorine substituted compounds higher lipophilicity and a typically greater metabolic stability than their non-fluorine containing counterparts [2]. Its importance in drug design is well illustrated by the fact that the annual contribution of organofluorine compounds to the FDA-approved small-molecule drugs has reached ca. $40-50 \%$ during the last few years [3]. 
Diethylaminosulfur trifluoride (DAST) is a mild, nucleophilic reagent that may convert non-phenolic alcohols, aldehydes and ketones, carboxylic acids, and sulfoxides into monofluorides, difluorides, acyl fluorides and $\alpha$-fluoro sulfides, respectively. Other than fluorination, however, DAST is known to catalyze the formation of many further building blocks valuable for medicinal chemistry, including various heterocycles through dehydration and intramolecular cyclization [4], sulfonamides through cross-coupling of arylboronic acids [5], aromatic thiols [6], etc. Previously, we reported the DAST catalyzed transformation of 20-hydroxyecdysone 2,3;20,22-diacetonide, and obtained 14- and/or 25fluorinated, and $\Delta^{14,15}$ analogs with or without a 25-fluorine moiety [7]. Several compounds showed stronger antiproliferative activity on various cancer cell lines than their parent ecdysteroid, and promising adjuvant antitumor properties when co-administered with doxorubicin. Further, all the compounds showed an increased potency as inhibitors of the ABCB1 transporter, commonly referred to as P-glycoprotein (Pgp) [7]. In contrast with the diacetonide, we found the sidechain cleaved ecdysteroid derivative poststerone to form cyclic sulfite esters that were only moderately active against some cancer cell lines [8].

From our previous extensive structure-activity relationship studies on the antitumor properties of ecdysteroids we found that their multidrug resistance decreasing activity does not rely on Pgp inhibition [9-12]. Because of this, our research on new antitumor ecdysteroid derivatives focuses on compounds that exert their activity without directly affecting drug efflux, and, as such, are free from the many potential problems (e.g., unwanted drug-drug interactions, altered pharmacokinetics of co-administered antitumor drugs, etc.) frequently attributed to efflux pump inhibitors. In the current study it was our aim to prepare such compounds by utilizing DAST as a chemical tool to the diversityoriented transformation of ecdysteroids.

\section{Results and Discussion}

\subsection{Chemistry}

\subsubsection{Preparation of starting materials for reactions with DAST}

We selected four apolar ecdysteroids including three sidechain-cleaved $(3,9,12)$ and a sidechain intact compound (16) as substrates for diethylaminusulfur-trifluoride (DAST)mediated transformations. Each of these compounds represent a derivative of a natural ecdysteroid (compounds 1, 8 and 15, respectively) used as a precursor in the semi-synthetic processes that afforded the selected intermediates for further transformations (Figure 1).

Selection of these compounds was based on our previous findings. These may be summed up in two key points: i) the adjuvant antitumor activity of ecdysteroids requires the presence of apolar functional groups, e.g. acetonide, particularly at the A-ring, and ii) removal of the sterol side-chain results in the loss of the compounds' direct Pgp inhibitory activity $[9,10]$.

Oxidative side-chain cleavage of ajugasterone $C(\mathbf{1})$ was achieved in good yield following our previously published procedure using hypervalent iodine reagent (diacetoxyiodo)benzene (PIDA) in methanol that afforded $11 \alpha$-hydroxypoststerone (2), which was subsequently converted to its 2,3-acetonide derivative (3) using phosphomolybdic acid (PMA) in acetone [9].

To increase the diversity of interesting, potentially bioactive substrates for our fluorination reactions, we selected another sidechain cleaved ecdysteroid, poststerone (8), for transformation. Poststerone is known as a natural metabolite of 20-hydroxyecdysone, the most abundant ecdysteroid existing in nature, and thus, it can be straightforwardly obtained in larger quantities from the oxidative side-chain cleavage of the parent compound [9]. To facilitate antitumor properties, poststerone (8) was also further converted to its corresponding 2,3-acetonide derivative (9).

Oximes and oxime ethers are valuable precursors in the preparation of bioactive nitrogen-containing scaffolds $[13,14]$. As a follow-up to our previous work with nitrogen- 
containing ecdysteroids [11], we transformed poststerone 2,3-acetonide (9) to its 20-oxime derivative by reacting the substrate with hydroxylamine in an ethanol solution. As an update to our former semi-synthetic strategy [15], the regioselectivity of the oximation can be significantly improved by changing the solvent from pyridine to ethanol that can afford the desired 20 -acetoxime product in $>80 \%$ yield, under simplified workup conditions.

Calonysterone 2-acetate (15) is a natural analogue of its parent compound calonysterone. This ecdysteroid was recently revealed in an in silico screening as a putative inhibitor of papain-like protease (PL pro), a major druggable target in SARS-CoV-2 treatment, affording potential anti-COVID-19 properties to the compound [16]. To increase potential regioselectivity in a subsequent DAST-catalyzed transformation, we carried out the acetonide protection of the molecule's 20,22-diols. Preparation of the above-described intermediates is shown in Figure 1.

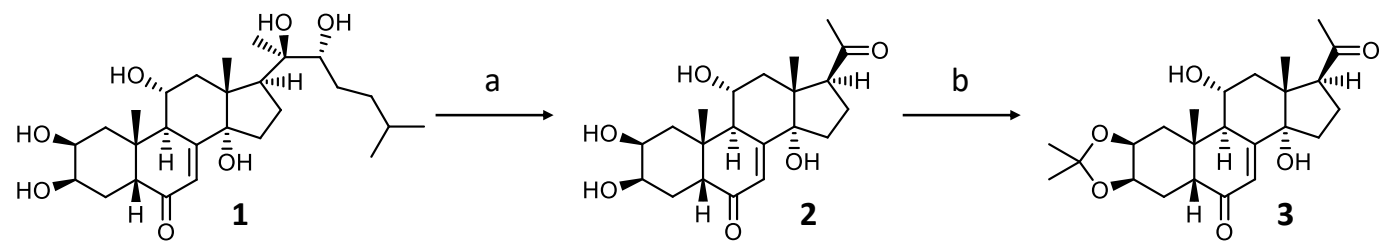

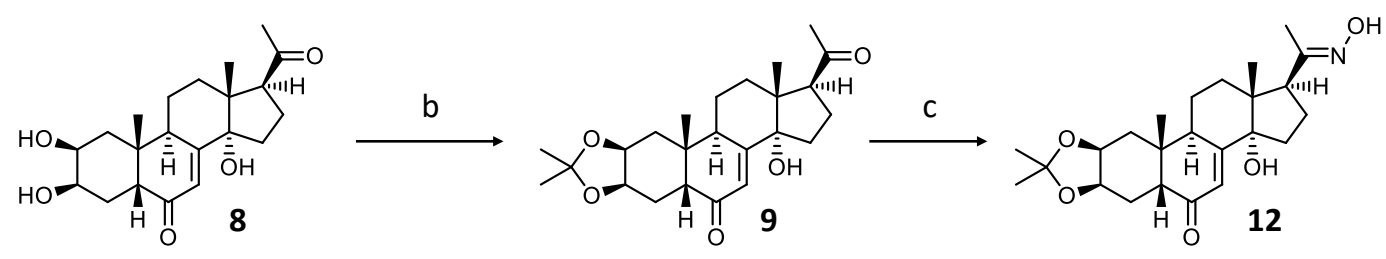

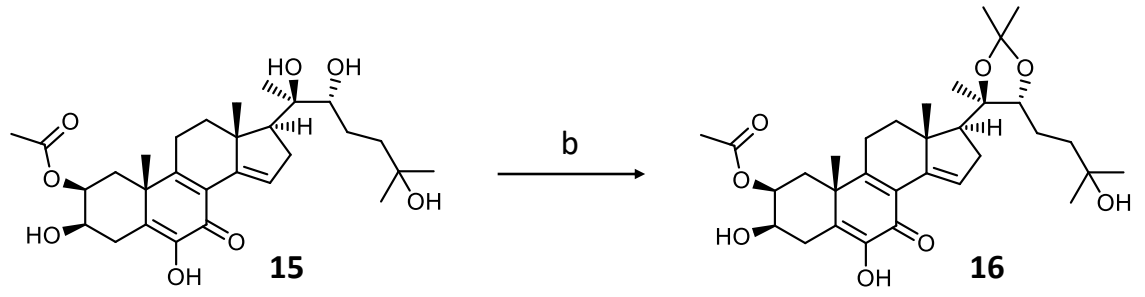

Figure 1. Semi-synthetic transformations of ajugasterone $\mathrm{C}(\mathbf{1})$, poststerone (8) and calonysterone 2-acetate (15). Reagents and conditions: a) PIDA, methanol, RT, 60 min; b) PMA, acetone, RT, $30 \mathrm{~min}$; c) $\mathrm{NH}_{2} \mathrm{OH} \cdot \mathrm{HCl}, \mathrm{KOH}, \mathrm{EtOH}, \mathrm{RT}, 24 \mathrm{~h}$.

2.1.2 DAST-mediated transformation of compounds 3, 9, 12, 16, 18, and structure elucidation of the products

Reactions were carried out according to our previously reported procedure [7]. DAST is known to react violently with water [17], thus, substrates were dissolved in anhydrous methylene-chloride, and the obtained solutions were cooled down to $-84{ }^{\circ} \mathrm{C}$ to avoid any undesired exothermic side-reactions. When the transformations were complete, the products were purified via single- or multi-step preparative HPLC separations. Following this strategy, we successfully obtained a total of 9 new ecdysteroid derivatives.

The NMR signals of the products were assigned by comprehensive one- and twodimensional NMR methods using widely accepted strategies $[18,19]$. Most ${ }^{1} \mathrm{H}$ assignments were accomplished using general knowledge of chemical shift dispersion with the aid of the proton-proton coupling pattern ( ${ }^{1} \mathrm{H}$ NMR spectra). ${ }^{1} \mathrm{H}$ NMR chemical shifts of overlapped signals were identified by 2D HSQC and HMBC experiments, and by utilising 1D selective ROESY (Rotating frame Overhauser Enchancement Spectroscopy) or NOESY responses and 1D selective TOCSY experiments. ${ }^{1} \mathrm{H}$ and ${ }^{13} \mathrm{C}$ NMR signal assignments for compounds 4-7, 10, 11, 13, 14, 15, 17, and 19 are compiled in Tables 1 and 2.

Table 1. ${ }^{1} \mathrm{H}$ and ${ }^{13} \mathrm{C}$ chemical shifts and $J_{C, F}$ coupling constants of compounds 4-7, 10 and 11 in $\mathrm{CDCl}_{3}$. 


\begin{tabular}{|c|c|c|c|c|c|c|c|c|c|c|c|c|}
\hline & \multicolumn{2}{|c|}{4} & \multicolumn{2}{|c|}{5} & \multicolumn{2}{|c|}{6} & \multicolumn{2}{|r|}{7} & \multicolumn{2}{|c|}{10} & \multicolumn{2}{|r|}{11} \\
\hline no. & ${ }^{1} \mathrm{H}$ & ${ }^{13} \mathrm{C}$ & ${ }^{1} \mathrm{H}$ & ${ }^{13} \mathrm{C}$ & ${ }^{1} \mathrm{H}$ & ${ }^{13} \mathrm{C}$ & ${ }^{1} \mathrm{H}$ & ${ }^{13} \mathrm{C}$ & ${ }^{1} \mathrm{H}$ & ${ }^{13} \mathrm{C}$ & ${ }^{1} \mathrm{H}$ & ${ }^{13} \mathrm{C}$ \\
\hline $1 \beta$ & 1.37 & 37.8 & 1.56 & 37.0 & 1.48 & 37.8 & 1.55 & 37.1 & 1.28 & 37.5 & 1.30 & 37.3 \\
\hline$\alpha$ & 2.04 & & 2.19 & & 2.25 & & 2.22 & & 1.96 & & 1.98 & \\
\hline 2 & 4.28 & 71.5 & 4.18 & 71.9 & 4.19 & 71.5 & 4.17 & 71.8 & 4.18 & 71.9 & 4.23 & 72.0 \\
\hline 3 & 4.31 & 71.8 & 4.15 & 71.2 & 4.16 & 71.5 & 4.17 & 71.2 & 4.28 & 71.6 & 4.29 & 71.4 \\
\hline $4 \beta$ & 2.17 & 26.9 & 2.05 & 28.2 & 2.17 & 29.0 & 2.08 & 28.2 & 2.17 & 26.7 & 2.09 & 28.2 \\
\hline$\alpha$ & 1.86 & & 1.86 & & 1.58 & & 1.86 & & 1.77 & & 1.91 & \\
\hline 5 & 2.44 & 49.7 & 2.45 & 50.6 & 2.47 & 50.2 & 2.48 & 50.7 & 2.36 & 50.7 & 2.39 & 50.6 \\
\hline 6 & & 201.6 & & 202.4 & & 202.3 & & 202.2 & & 201.9 & & 201.9 \\
\hline 7 & 5.88 & 121.2 & 5.82 & 119.5 & 6.12 & 117.5 & 5.91 & $121.8 \mathrm{~d} 7 \mathrm{~Hz}$ & 6.10 & 121.5 & 5.91 & $124.1 \mathrm{~d} 6.7 \mathrm{~Hz}$ \\
\hline 8 & & 158.1 & & 152.2 & & 141.8 & & $149.5 \mathrm{~d} 19 \mathrm{~Hz}$ & & 152.7 & & $155.0 \mathrm{~d} 20 \mathrm{~Hz}$ \\
\hline 9 & 3.39 & 38.5 & & 135.7 & & 135.9 & & 135.4 & 2.41 & 38.6 & 2.69 & 35.7 \\
\hline 10 & & 38.9 & & 39.4 & & 40.4 & & 39.4 & & 38.4 & & 37.6 \\
\hline $11 \beta$ & 5.78 & 124.5 & 6.17 & 130.8 & 6.17 & 130.1 & 6.18 & 130.6 & 1.72 & 20.5 & 1.63 & 20.6 \\
\hline$\alpha$ & & & & & & & & & 1.84 & & 1.84 & \\
\hline $12 \beta$ & 6.33 & 133.7 & 2.41 & 36.0 & 2.75 & 40.9 & 2.46 & $35.9 \mathrm{~d} 6 \mathrm{~Hz}$ & 2.31 & 38.7 & 1.91 & $30.4 \mathrm{~d} 4.5 \mathrm{~Hz}$ \\
\hline$\alpha$ & & & 2.87 & & 2.57 & & 2.81 & & 1.74 & & 2.13 & \\
\hline 13 & & 51.0 & & 46.9 & & 46.0 & & $46.9 \mathrm{~d} 20 \mathrm{~Hz}$ & & 47.3 & & $48.2 \mathrm{~d} 19.5 \mathrm{~Hz}$ \\
\hline 14 & & 84.6 & & 83.7 & & 142.9 & & $106.0 \mathrm{~d} 168 \mathrm{~Hz}$ & & 146.1 & & $107.3 \mathrm{~d} ; 166 \mathrm{~Hz}$ \\
\hline $15 \beta$ & 2.08 & 28.6 & 2.05 & 31.1 & 6.28 & 128.4 & 2.04 & $28.5 \mathrm{~d} 25 \mathrm{~Hz}$ & 5.97 & 128.2 & 1.98 & $28.4 \mathrm{~d} 28 \mathrm{~Hz}$ \\
\hline$\alpha$ & 1.75 & & 1.86 & & & & 2.14 & & & & & \\
\hline $16 \beta$ & 2.30 & 21.8 & 2.31 & 21.5 & 2.98 & 32.0 & 2.34 & 21.5 & 2.93 & 31.6 & 2.32 & 21.1 \\
\hline$\alpha$ & 2.09 & & 2.01 & & 2.48 & & 2.03 & & 2.36 & & 1.95 & \\
\hline 17 & 3.37 & 55.2 & 3.34 & 58.4 & 3.08 & 64.1 & 3.22 & 58.6 & 3.06 & 64.9 & 3.17 & 58.8 \\
\hline 18 & 0.73 & 21.1 & 0.64 & 17.4 & 0.84 & 19.4 & 0.67 & $16.9 \mathrm{~d} 5 \mathrm{~Hz}$ & 0.85 & 18.9 & 0.65 & $16.5 \mathrm{~d} 4 \mathrm{~Hz}$ \\
\hline 19 & 0.89 & 23.9 & 1.23 & 29.6 & 1.14 & 30.1 & 1.20 & 29.7 & 0.98 & 23.2 & 1.00 & 23.7 \\
\hline 20 & & 208.9 & & 209.2 & & 207.6 & & 208.9 & & 207.8 & & 208.3 \\
\hline 21 & 2.22 & 31.0 & 2.17 & 31.0 & 2.22 & 31.0 & 2.19 & 31.0 & 2.20 & 31.2 & 2.17 & 31.3 \\
\hline 22 & & & & 108.4 & & 108.5 & & 108.5 & & 108.3 & & 108.3 \\
\hline$\beta \mathrm{Me}$ & 1.51 & & 1.52 & 28.5 & 1.52 & 28.5 & 1.53 & 28.5 & 1.50 & 28.5 & 1.50 & 28.5 \\
\hline$\alpha \mathrm{Me}$ & 1.35 & & 1.32 & 26.3 & 1.32 & 26.4 & 1.33 & 26.4 & 1.34 & 26.3 & 1.34 & 26.4 \\
\hline HO-14 & 2.37 & & 1.92 & & & & 1.92 & & & & & \\
\hline
\end{tabular}

Table 2. ${ }^{1} \mathrm{H}$ and ${ }^{13} \mathrm{C}$ chemical shifts and $J_{\mathrm{C}, \mathrm{F}}$ coupling constants of compounds $13, \mathbf{1 4}, 17$ in $\mathrm{CDCl}_{3}, 15$ in $\mathrm{CD}_{3} \mathrm{OD}$ and 19 in DMSO-d6.

\begin{tabular}{|c|c|c|c|c|c|c|c|c|c|c|}
\hline & \multicolumn{2}{|c|}{13} & \multicolumn{2}{|c|}{14} & \multicolumn{2}{c|}{17} & \multicolumn{2}{c|}{19} \\
\hline no. & ${ }^{1} \mathrm{H}$ & ${ }^{13} \mathrm{C}$ & ${ }^{1} \mathrm{H}$ & ${ }^{13} \mathrm{C}$ & ${ }^{13} \mathrm{H}$ & ${ }^{13} \mathrm{C}$ & ${ }^{13} \mathrm{H}$ & ${ }^{13} \mathrm{C}$ & ${ }^{1} \mathrm{H}$ & ${ }^{13} \mathrm{C}$ \\
\hline $1 \beta$ & 1.25 & 37.5 & 1.28 & 37.3 & 2.47 & 40.5 & 1.48 & 36.3 & 1.89 & $36.4 \mathrm{~d} 11 \mathrm{~Hz}$ \\
\hline$\alpha$ & 1.95 & & 1.98 & & 1.47 & & 2.25 & & 1.07 & \\
\hline $2 \beta$ & & 71.9 & & 72.0 & & 73.0 & & 73.1 & 1.70 & $28.8 \mathrm{~d} 18 \mathrm{~Hz}$ \\
\hline$\alpha$ & 4.16 & & 4.23 & & 5.20 & & 4.19 & & 1.99 & \\
\hline 3 & 4.26 & 71.6 & 4.29 & 71.3 & 3.64 & 71.8 & 2.01 & 35.7 & 4.39 & $92.8 \mathrm{~d} 174 \mathrm{~Hz}$ \\
\hline $4 \beta$ & 2.14 & 26.7 & 2.08 & 26.27 & 2.52 & 28.3 & 1.43 & 11.0 & 2.45 & $39.4 \mathrm{~d} 19 \mathrm{~Hz}$ \\
\hline$\alpha$ & 1.76 & & 1.92 & & 3.24 & & 1.58 & & 2.45 & \\
\hline 5 & 2.34 & 50.7 & 2.39 & 50.7 & & 131.3 & & 40.2 & & $139.4 \mathrm{~d} 12 \mathrm{~Hz}$ \\
\hline 6 & & 202.2 & & 202.2 & & 144.8 & & 189.5 & 5.40 & 123.0 \\
\hline
\end{tabular}




\begin{tabular}{|c|c|c|c|c|c|c|c|c|c|c|}
\hline 7 & 6.06 & 120.9 & 5.88 & $123.37 \mathrm{~Hz}$ & & 181.4 & & 144.6 & $1.99 ; 1.54$ & 31.9 \\
\hline 8 & & 153.3 & & $155.4 \mathrm{~d} 20 \mathrm{~Hz}$ & & 125.0 & & 118.3 & 1.46 & 31.87 \\
\hline 9 & 2.38 & 38.7 & 2.69 & 35.8 & & 164.5 & & 136.2 & 0.93 & 50.0 \\
\hline 10 & & 38.5 & & 37.7 & & 41.8 & & 44.2 & & 36.5 \\
\hline $11 \beta$ & 1.60 & 20.3 & 1.55 & 20.2 & 2.60 & 25.4 & 6.00 & 122.5 & 1.50 & 21.1 \\
\hline$\alpha$ & 1.77 & & 1.80 & & 2.60 & & & & 1.50 & \\
\hline $12 \beta$ & 2.02 & 37.0 & 1.61 & $28.7 \mathrm{~d} 5 \mathrm{~Hz}$ & 2.28 & 37.8 & 2.54 & 40.0 & 2.03 & 39.7 \\
\hline$\alpha$ & 1.59 & & 2.05 & & 1.52 & & 2.21 & & 1.18 & \\
\hline 13 & & 46.9 & & $47.9 \mathrm{~d} 19 \mathrm{~Hz}$ & & 47.9 & & 46.5 & & 42.3 \\
\hline 14 & & 147.5 & & $105.5 \mathrm{~d} 166 \mathrm{~Hz}$ & & 142.4 & & 143.5 & 1.00 & 56.7 \\
\hline $15 \beta$ & 5.93 & 126.5 & 2.09 & $27.7 \mathrm{~d} 28 \mathrm{~Hz}$ & 6.85 & 128.2 & 6.81 & 133.2 & 1.08 & 24.3 \\
\hline$\alpha$ & & & 1.95 & & & & & & 1.58 & \\
\hline $16 \beta$ & 2.21 & 36.0 & 1.50 & 26.9 & 2.71 & 32.7 & 2.65 & 32.5 & 1.27 & 28.2 \\
\hline$\alpha$ & 2.67 & & 2.41 & & 2.25 & & 2.45 & & 1.85 & \\
\hline 17 & 4.41 & 60.3 & 4.60 & 55.4 & 1.99 & 56.5 & 1.95 & 55.2 & 1.10 & 56.2 \\
\hline 18 & 0.89 & 17.2 & 0.71 & $15.3 \mathrm{~d} 4 \mathrm{~Hz}$ & 1.07 & 18.3 & 0.95 & 19.7 & 0.69 & 11.9 \\
\hline 19 & 0.96 & 23.2 & 1.00 & 23.4 & 1.44 & 27.3 & 1.19 & 26.4 & 1.04 & 19.3 \\
\hline 20 & & 170.2 & & 170.1 & & 77.3 & & 82.9 & 1.38 & 35.8 \\
\hline 21 & 2.02 & 23.4 & 2.02 & 23.6 & 1.26 & 20.5 & 1.16 & 21.2 & 0.93 & 18.7 \\
\hline 22 & & 108.3 & & 108.3 & 3.38 & 78.7 & 3.71 & 81.4 & $1.35 ; 1.00$ & 36.2 \\
\hline$\beta \mathrm{Me}$ & 1.49 & 28.5 & 1.50 & 28.6 & & & 1.52 & 28.5 & 1.52 & \\
\hline$\alpha \mathrm{Me}$ & 1.33 & 26.3 & 1.34 & 26.3 & & & 1.32 & 26.4 & 1.32 & \\
\hline 23 & & & & & $1.62 ; 1.31$ & 27.3 & $1.45 ; 1.42$ & 23.4 & $1.34 ; 1.15$ & 23.8 \\
\hline 24 & & & & & $1.81 ; 1.43$ & 42.4 & $1.54 ; 1.38$ & 41.4 & 1.14 & 39.5 \\
\hline 25 & & & & & & 71.4 & & 68.7 & & 28.0 \\
\hline 26 & & & & & 1.17 & 28.9 & & 29.0 & 0.87 & 22.6 \\
\hline 27 & & & & & 1.20 & 30.0 & & 29.8 & 0.88 & 22.8 \\
\hline 28 & & & & & & & & 106.3 & & \\
\hline$\beta \mathrm{Me}$ & & & & & & & 1.26 & 29.2 & & \\
\hline$\alpha \mathrm{Me}$ & & & & & & & 1.35 & 26.9 & & \\
\hline $\mathrm{NH}$ & 5.80 & & 5.57 & & & & & & & \\
\hline $\mathrm{HO}-7$ & & & & & & & 9.29 & & & \\
\hline
\end{tabular}

To facilitate understanding of the structure elucidation steps, we prepared the yet unpublished complete ${ }^{1} \mathrm{H}$ and ${ }^{13} \mathrm{C}$ NMR signal assignments of the intermediate compound 3 (Figure 2), aided by its ${ }^{1} \mathrm{H}, \mathrm{DEPTQ}$, edHSQC and HMBC spectra. In the followings, structure elucidation of the sidechain shortened derivatives (compounds 4-7, 10, 11, 13 and 14) are described in comparison with these results. 


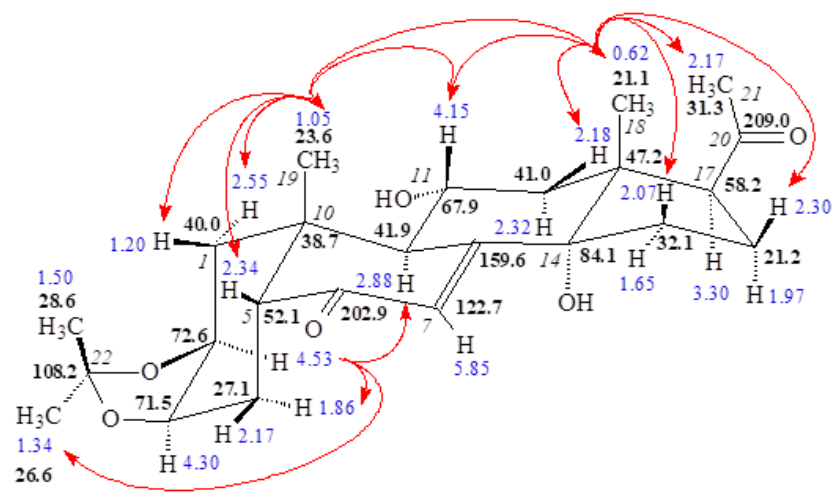

Figure 2. Stereostructure of compound $3\left(\mathrm{C}_{24} \mathrm{H}_{34} \mathrm{O}_{6}\right)$ along with its ${ }^{1} \mathrm{H}$ (blue numbers) and ${ }^{13} \mathrm{C}$ NMR (black numbers in bold) signal assignments. Cursive numbers give the atomic numbering. The $\alpha$ or $\beta$ orientation of hydrogen atoms was determined by selROE measurements starting from $\mathrm{H} \alpha-2$ (4.53ppm), $\mathrm{H}_{3}-18$ (0.62 ppm), and $\mathrm{H}_{3}-19$ (1.02 ppm), and red arrows show spatial proximities proven this way.

For compound 4, HRMS data indicated an elemental composition of $\mathrm{C}_{24} \mathrm{H}_{32} \mathrm{O}_{5}$ (Supporting material Fig. S56), the molecule consists of one oxygen and two hydrogen atoms less than its parent compound 3, and the number of its double bond equivalents increased to 9. The most characteristic changes in the NMR spectra, as compared with that of 3 , indicated the disappearance of the $\mathrm{HO}-\mathrm{CH}-\mathrm{CH}_{2}$ group in the $\mathrm{B}$ ring $(\delta \mathrm{C}-1167.9, \delta \mathrm{H}-11$ 4.25 ; $\delta \mathrm{C}-1241.0, \delta \mathrm{H} 2-122.32,2.18 \mathrm{ppm}$ ) and presence of a new $-\mathrm{CH}=\mathrm{CH}-$ group $(\delta \mathrm{C}-11$ $\left.124.5, \delta \mathrm{H}-115.78, J_{11,12}=10 \mathrm{~Hz} ; \delta \mathrm{C}-12133.7, \delta \mathrm{H}-126.33 J_{11,12}=10 \mathrm{~Hz}\right)$. To achieve the complete ${ }^{1} \mathrm{H}$ and ${ }^{13} \mathrm{C}$ NMR signal assignment in $\mathrm{CDCl}_{3},{ }^{1} \mathrm{H}$ and selTOCSY on $\mathrm{H}-5, \mathrm{H}-12$ and $\mathrm{H}-$ 7 spectra (Fig. S1), selNOESY on $8 \mathrm{Me}, \mathrm{H}_{3}-19$ and $\mathrm{H}_{3}-18$ (Fig. S2), DEPTQ (Fig. S3), edHSQC (Fig. S4) and HMBC (Fig. S5) spectra were utilized. SelNOESY experiments on $\mathrm{H}_{3}-18$ and $\mathrm{H}_{3}-19$ (Fig. S2) unambiguously differentiated $\mathrm{H}-11$ and $\mathrm{H}-12$ signals, furthermore the 0.62/41.0 ppm H3-19/C-12 HMBC cross-peak (Fig. S5) confirmed the $\Delta^{11,12}$ position of the new double bond. The chemical shifts of all other ${ }^{1} \mathrm{H}$ and ${ }^{13} \mathrm{C}$ NMR signals in compound 4 are similar to that of 3 .

According to the HRMS measurement, the molecular formula of compound 5 is identical to that of compound $4 \mathrm{C}_{24} \mathrm{H}_{32} \mathrm{O}_{5}$ (Fig. S57) and number of its double bond equivalents is also 9 , both compounds are structural isomers. The ${ }^{1} \mathrm{H}$ and DEPTQ spectra of 5 revealed in this compound the appearance of one tri-substituted $\mathrm{C}=\mathrm{CH}$ - double bond ( $\delta \mathrm{C}-9$ 135.7; $\delta \mathrm{C}-11130.8, \delta \mathrm{H}-116.17 \mathrm{ppm})$. The following spectra were used for NMR study of $5:{ }^{1} \mathrm{H}$ and selTOCSY on H-7 spectra (Fig. S6), selNOESY on $\alpha \mathrm{Me}, \mathrm{H}_{3}-19$ and $\mathrm{H}_{3}-18$ (Fig. S7), DEPTQ (Fig. S8), edHSQC (Fig. S9) and HMBC (Fig. S10) spectra were utilized. The 1.23/135.7 ppm H3-19/C-9 HMBC response (Fig. S9) revealed the C-9 position of the quaternary $\mathrm{C}=$ atom, i.e. the $\Delta^{9,11}$ position of the new double bond. In addition to the $0.64 / 36.0$ ppm $\mathrm{H}_{3}-18 / \mathrm{C}-12 \mathrm{HMBC}$ cross-peak confirmed the existence of $\mathrm{H}_{2} \mathrm{C}$ group in this position. All of other ${ }^{1} \mathrm{H}$ and ${ }^{13} \mathrm{C}$ NMR signals in 5 are highly similar to that of 4 .

The molecular formula of compound 6 was established as $\mathrm{C}_{24} \mathrm{H}_{30} \mathrm{O}_{4}$ by means of HRMS (Fig. S58), i.e. the number of double bond equivalents rose to 10 . The ${ }^{1} \mathrm{H}$ (Fig. S11) and DEPTQ (Fig. S13) spectra of 6 confirmed in this compound the presence of two trisubstituted $\mathrm{C}=\mathrm{CH}$ - double bonds $(\delta \mathrm{C}-9135.9 ; \delta \mathrm{C}-11130.1, \delta \mathrm{H}-116.17 \mathrm{ppm})$ and $(\delta \mathrm{C}-14$ $142.9 ; \delta \mathrm{C}-15128.4, \delta \mathrm{H}-156.28 \mathrm{ppm})$. The $\Delta^{9,11}$ position is supported by the $1.14 / 135.9 \mathrm{ppm}$ $\mathrm{H}_{3}-19 / \mathrm{C}-9$ HMBC response, whereas the 0.84/142.9 ppm H3-18/C-14 HMBC cross-peak confirmed the $\Delta^{14,15}$ arrangement (Fig. S15) of the other double bond, respectively, formed by the elimination of the 14-OH group. The edHSQC (Fig. S14) experiment served the selective identification of $\mathrm{CH}_{2}$ and $\mathrm{CH} / \mathrm{CH}_{3}{ }^{1} \mathrm{H}$ and ${ }^{13} \mathrm{C}$ signals, and supplemented by the results of the selNOESY measurements on $\alpha \mathrm{Me}, \mathrm{H}_{3}-19$ and $\mathrm{H}_{3}-18$ (Fig. S2) even the stereochemical assignment of ${ }^{1} \mathrm{H}$ signal assignment has been achieved.

The reaction of 3 with DAST resulted also compound 7, and its elemental composition was established as $\mathrm{C}_{24} \mathrm{H}_{31} \mathrm{O}_{4} \mathrm{~F}$ (Fig. S59), number of double bond equivalents is 9. The 
${ }^{1} \mathrm{H}$ (Fig. S16) and DEPTQ (Fig. S16) spectra and the 1.20/135.7 ppm H3-19/C-9 HMBC response (Fig. S19) revealed the $\Delta^{9,11}$ position of the new tri-substituted $\mathrm{C}=\mathrm{CH}-$ double bond ( $\delta \mathrm{C}-9135.7 ; \delta \mathrm{C}-11130.6, \delta \mathrm{H}-116.18 \mathrm{ppm}$ ), which was resulted by the splitting of the 11-OH group. Previously, we reported the NMR data of 14-fluorinated ecdysteroid derivatives obtained by DAST catalyzed transformation [7]. It was found that changes an $\mathrm{HO}$ - 14 group to a F -14 manifests in $~ 25$ ppm paramagnetic shift on $\delta \mathrm{C}-14$, and at the same time in dublet multiplicity of the signal, caused by ${ }^{1} \mathrm{C}, \mathrm{F} \sim 165 \mathrm{~Hz}$ coupling. It is worth noting that the geminal, vicinal and ${ }^{\mathrm{n}} \mathrm{C}_{\mathrm{C}, \mathrm{F}}$ couplings result characteristic $\sim 25 \mathrm{~Hz}, \sim 10 \mathrm{~Hz}$ and $\sim 3 \mathrm{~Hz}$ signal splittings, respectively. The 0.67/106.0 ppm H3-18/C-14 HMBC cross-peak (Fig. S19) and its doublet multiplicity $\left({ }^{1} J_{C, F} \sim 168 \mathrm{~Hz}\right)$ clearly justified the fluorination in C14 position. The edHSQC (Fig. S18) spectrum served the selective identification of $\mathrm{CH}_{2}$ and $\mathrm{CH} / \mathrm{CH}_{3}{ }^{1} \mathrm{H}$ and ${ }^{13} \mathrm{C}$ signals. It is important to mention that the selROESY measurements on $\mathrm{H}_{3}-19$ and $\mathrm{H}_{3}-18$ (Fig. S16) revealed not only the $\alpha$ or $\beta$ position of the hydrogen atoms, but clearly demonstrated the trans $\mathrm{C} / \mathrm{D}$ ring-junction and thus the $\alpha$ position of the 14-fluorine atom.

Recently we have reported the NMR characteristics of posterone and a series of posterone 2,3-dioxalanes including also compound 9 [9]. The DAST-catalyzed transformation of posterone 2,3-acetonide afforded compound 10. Its HRMS data indicated an elemental composition of $\mathrm{C}_{24} \mathrm{H}_{32} \mathrm{O}_{4}$ (Fig. S60), the molecule consists of one oxygen and two hydrogen atoms less than its parental $\mathbf{9}$, and the number of its double bond equivalents rose to 9 . These suggested that water elimination took place. This was confirmed by the ${ }^{1} \mathrm{H}$ (Fig. S20), DEPTQ (Fig. S22) and edHSQC (Fig. 23) spectra indicating the presence of a new tri-substituted $\mathrm{C}=\mathrm{CH}-$ double bond $(\delta \mathrm{C}-14146.1 ; \delta \mathrm{C}-15128.2, \delta \mathrm{H}-155.97 \mathrm{ppm})$. The 0.85/146.1 ppm H3-18/C-14 HMBC cross-peak confirmed the $\Delta^{14,15}$ arrangement (Fig. S24 and 25). The selTOCSY experiment on H-15 and Ho--1 (Fig. S20) served the separate recognition of the ${ }^{1} \mathrm{H}$ signals in the $\mathrm{A}$ and $\mathrm{D}$ rings, whereas selNOESY on signals $\beta \mathrm{Me}, \mathrm{H}_{3}-$ 19 and $\mathrm{H}_{3}-18$ (Fig. S21) supported the $\alpha$ or $\beta$ assignment of hydrogen atoms.

Compound 11 was obtained also from DAST-catalyzed transformation of $\mathbf{9}$. The elemental composition is $\mathrm{C}_{24} \mathrm{H}_{33} \mathrm{O} \mathrm{O}_{\mathrm{F}}$ (Fig. S60), obtained by HRMS, and the number of double bond equivalents is 8 . These results suggested that the $\mathrm{HO}$ - group was exchanged to $-\mathrm{F}$ atom. This was completely confirmed by the NMR data (Fig. $26-31$ ). The 0.65/107.3 ppm $\mathrm{H}_{3}-18 / \mathrm{C}-14 \mathrm{HMBC}$ cross-peak (Fig. S30, S31) and its doublet multiplicity $\left({ }^{1} \mathrm{JC}_{\mathrm{C}, \mathrm{F}}=166 \mathrm{~Hz}\right)$ perfectly justified the fluorination in C-14 position. The selNOESY experiments on signals $\beta \mathrm{Me}, \mathrm{H}_{3}-19$ and $\mathrm{H}_{3}-18$ revealed the stereochemistry of hydrogen atoms, and perfectly supported trans $\mathrm{C} / \mathrm{D}$ ring-junction and in this way the $\mathrm{F} \alpha-14$ substitution.

Based on HRMS data, an elemental composition of $\mathrm{C}_{24} \mathrm{H}_{33} \mathrm{O}_{4} \mathrm{~N}$ (Fig. S60) was established for compound 13. All of its ${ }^{1} \mathrm{H}$ and ${ }^{13} \mathrm{C}$ spectra: ${ }^{1} \mathrm{H}$ and selTOCSY on $\mathrm{H}-17$ and $\mathrm{H}-3$ spectra (Fig. S32), selROESY on $\mathrm{H}_{3}-19$ and $\mathrm{H}_{3}-18$ (Fig. S33), DEPTQ (Fig. S34), edHSQC (Fig. S35 and 37) and HMBC (Fig. S36 and 37) spectra are quite similar to spectra measured for compound 10. Characteristic changes were detected only for the $\mathrm{CH}_{3}-\mathrm{C}=\mathrm{O}(2.02 \mathrm{~s} ; 23.4$ and $170.2 \mathrm{ppm}$ ) group, and appeared a new $\delta \mathrm{NH}$ signal $(5.80 \mathrm{~d} J \mathrm{H}-17, \mathrm{NH}=9.0 \mathrm{~Hz})$. The measured $37.6 \mathrm{ppm}$ diamagnetic shift of the $\mathrm{C}=\mathrm{O}$ signal in relation to compound 10 , is in accord with one amide group. The 0.67/106.0 ppm H3-18/C-14 HMBC cross-peak (Fig. S19) and its doublet multiplicity $\left({ }^{1} \mathrm{C}_{\mathrm{C}, \mathrm{F}} \sim 168 \mathrm{~Hz}\right)$ clearly justified the fluorination in C-14 position.

For compound 14 HRMS data indicated an elemental composition of $\mathrm{C}_{24} \mathrm{H}_{34} \mathrm{O}_{4} \mathrm{NF}$ (Supporting material Fig. S56), the molecule consists of one fluorine and one hydrogen atom more than in the former compound 13, and the number of its double bond equivalents decreased to 8 . Comparing the ${ }^{1} \mathrm{H}$ (Fig. S38), DEPTQ (Fig. S41) and edHSQC (Fig. S42) spectra with the fairly similar spectra of compound 13, the presence of the $\mathrm{HN}-\mathrm{CO}$ $-\mathrm{CH}_{3}(\delta \mathrm{NH} 5.57,170.1$ and $2.02 \mathrm{~s} ; 23.6 \mathrm{ppm}$ ) amide group in position 17 is straightforward. The disappearance of the signals for the $\Delta^{14,15}$ moiety $(141.6$ and $128.2 ; 5.97 \mathrm{ppm})$ and the appearance of characteristic $\left({ }^{1} J_{C, F}=165 \mathrm{~Hz}\right)$ signal splitting at $105.5 \mathrm{~d}$ ppm revealed the fluorination. The $0.71 / 105.5 \mathrm{ppm} \mathrm{H}-18 / \mathrm{C}-14 \mathrm{HMBC}$ correlation (Fig. S44) confirmed the fluorination in C-14 position. The selNOESY experiments on signals $\mathrm{NH}, \mathrm{H}_{3}-19$ and $\mathrm{H}_{3}-18$ (Fig. S40) revealed the characteristic hydrogen/hydrogen steric proximities, and perfectly 
supported trans C/D ring-junction and in this way the $14-\mathrm{F} \alpha$ substitution. Despite of strong ${ }^{1} \mathrm{H}$ signal overlaps the separate identification of spin-systems of $\mathrm{A}, \mathrm{C}$ and $\mathrm{D}$ rings was successfully implemented by selTOCSY on H-3, H-9 and H-17 (Fig. 39). The edHSQC spectrum (Fig. 43) with insertion of the one-dimensional selTOCSY on H-17 spectrum (Fig. 39) proved to be very effective in assignment of close and broad signals.

The natural product calonysterone 2-acetate $\mathbf{1 5}$ served as the starting material for further synthesis, for reference, its ${ }^{1} \mathrm{H}$ and ${ }^{13} \mathrm{C}$ NMR data are inserted to Table 2.

The reaction of calonysterone 2-acetate 20,22-acetonide (16) with DAST resulted in 17. HRMS revealed an elemental composition of $\mathrm{C}_{32} \mathrm{H}_{44} \mathrm{O}_{7}$ (Fig. S64) for this compound, suggesting that water elimination took place. The number of double bond equivalents increased to 11, therefore, this compound contains five double bonds and six rings. The presence of seven methyl signals in the ${ }^{1} \mathrm{H}$ (Fig. S45) and DEPTQ (Fig. S47) spectra suggested that the sterol side chain at C-17 and the 2-acetate group remained intact. Appearance of the characteristic signals of the $\Delta^{14,15}$ moiety $(\delta \mathrm{C}-14145.3 ; \delta \mathrm{C}-15133.2, \delta \mathrm{H}-156.81$ ppm) revealed the unchanged steroid D-ring. Based on the HSQC (Fig. S48) experiment, the signals of the H-C-3 group $(2.01 ; 35.7$ ppm) showed an extra high diamagnetic shift. This means that elimination of the $3-\mathrm{OH}$ group took place. The selTOCSY experiment on $\mathrm{H}-2$ (Fig. S46) also identified the $\delta \mathrm{H}_{2}-4$ signals (1.42 and $1.58 \mathrm{ppm}$ ). The extreme high deshielding on the corresponding $\delta \mathrm{C}-4(11.0 \mathrm{ppm})$ (Fig. S48) clearly indicated the formation of a cyclopropane ring between C-3 and C-5, and thus the existence of a five-membered A-ring. At the same time the quaternary C-5 atom changed to an $\mathrm{sp}^{3}$ carbon and its $\delta 40.2$ ppm chemical shift is identified by the $\mathrm{H}_{3}-19 / \mathrm{C}-5$ cross-peak in the HMBC spectrum (Fig. S48). The $\mathrm{H}_{3}-19 / \mathrm{C}-9$ (1.19/136.22 ppm) HMBC correlation revealed a $\Delta^{9,11}$ double bond in the B ring. SelNOESY experiments on $\mathrm{H}_{3}-18$ and $\mathrm{H}_{3}-19$ (Fig. S46) unambiguously differentiated $\alpha / \beta$ positions of hydrogen atoms and differentiated between the methylene hydrogens in the cyclopropane ring. The significant changes in the NMR chemical shifts in the $B$ and $C$ rings can be well explained with the rearrangement of double bonds of the 6-hydroxy- $\Delta^{5,6-7-o n e-\Delta^{8,9}}$ chromophore of calonysterone. This is in agreement with our previous report on the NMR characteristics of calonysterone and isocalonysterone [20].

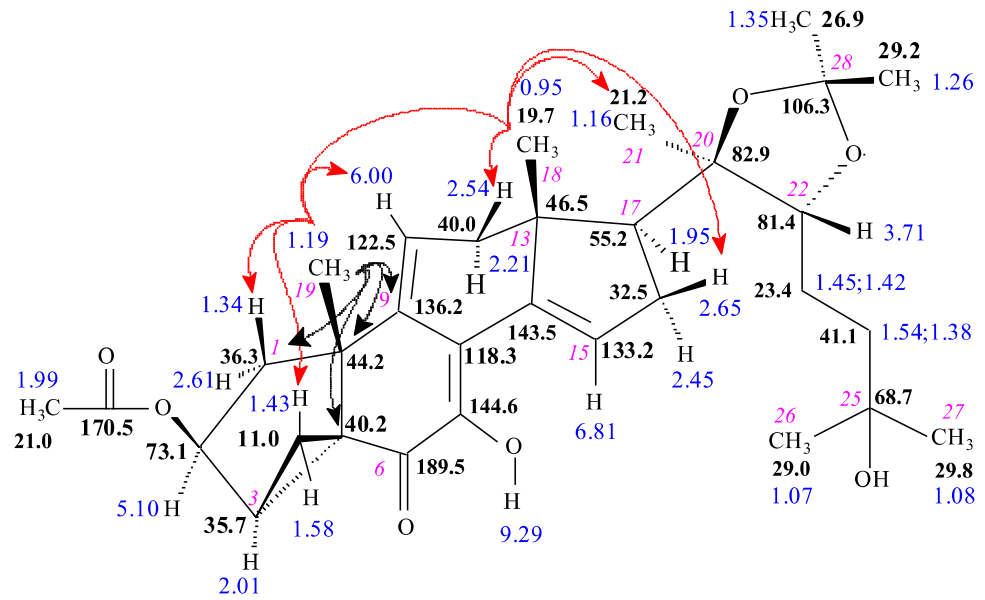

Figure 3. Stereostructure of compound 17 along with ${ }^{1} \mathrm{H}$ (blue) and ${ }^{13} \mathrm{C}$ NMR (black) chemical shifts. Cursive numbers denote the atomic numbering. The red arrows show spatial proximities determined by selNOE measurements and black arrows indicate characteristic HMBC responses.

The reactions carried out with DAST, and structures of the compounds obtained are presented in Figure 2. 


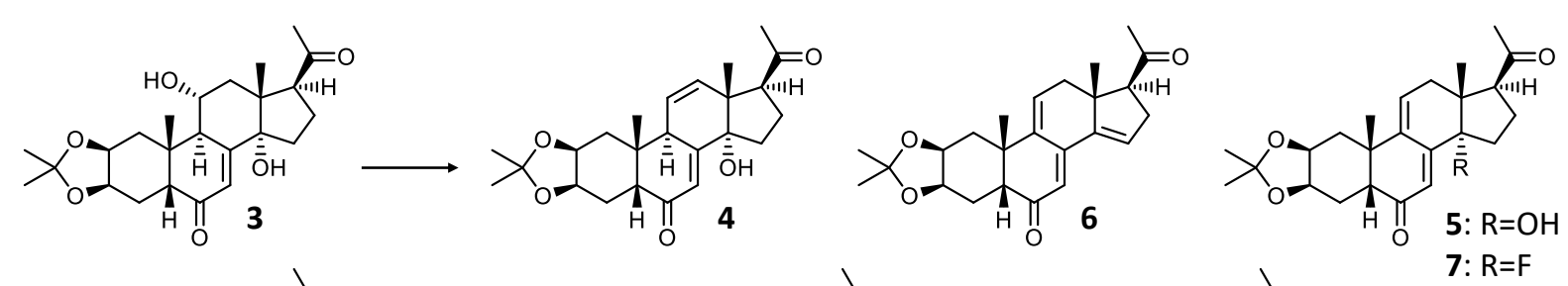

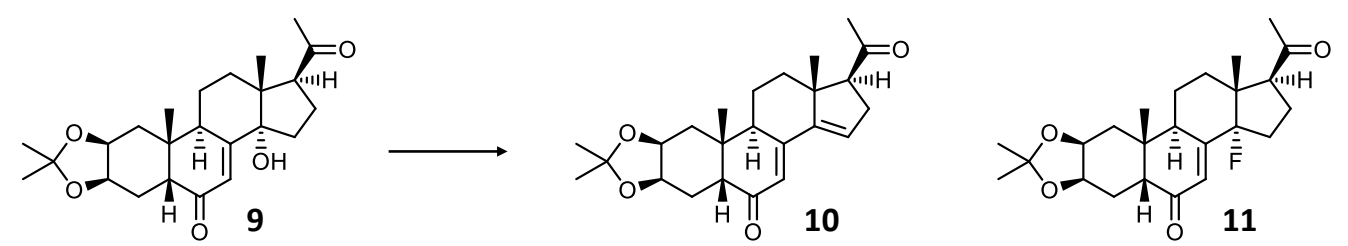

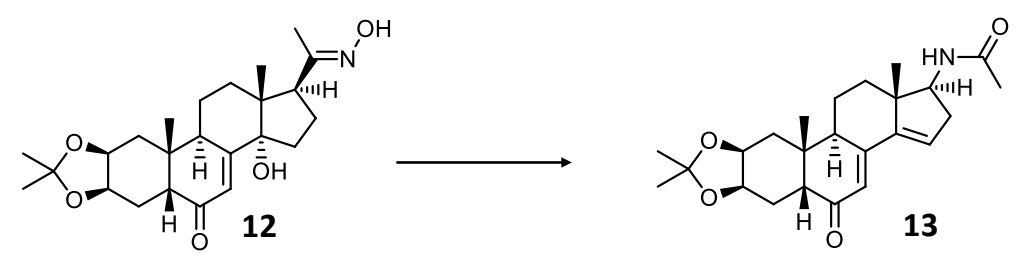

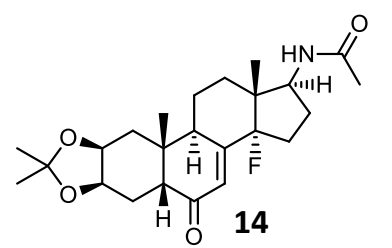

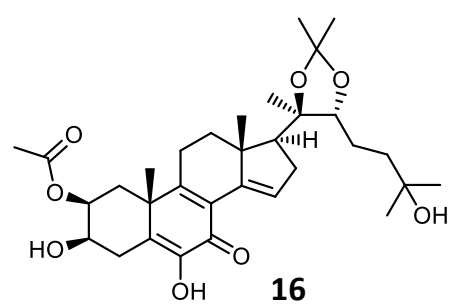

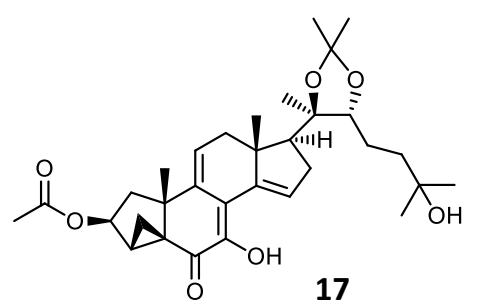

Figure 4. Structures of products obtained by the DAST-mediated transformation of compounds $3, \mathbf{9}, \mathbf{1 2}, \mathbf{1 6}, \mathbf{1 8}$. Reagents and conditions: DAST, anh. $\mathrm{CH}_{2} \mathrm{Cl}_{2},-84^{\circ} \mathrm{C} \rightarrow$ room temperature, $70 \mathrm{~min}$.

In general, the DAST-mediated transformation of ecdysteroids afforded structurally diverse products including ecdysteroid anhydro derivatives (e.g., compound 10) formed by water elimination, fluorine substituted analogues (e.g., compound 11), compounds with both newly formed olefins and fluoride groups (e.g., compound 7), two new acetamides (13 and 14) and a unique new ecdysteroid with a cyclopropane ring (17).

The ability of DAST to promote the skeletal rearrangement of oximes to substituted amides (known as Beckmann-rearrangement) was previously reported [21]. Additionally, DAST was recently found to be a useful reagent to induce the Beckmann-fragmentation of $\alpha$-oximinoketones resulting in the preparation of aryloyl and aliphatic acyl fluorides [22]. In accordance with the previous reports, the reaction of ecdysteroid 20-acetoximes with DAST could effectively furnish the corresponding amides and resulted in two different Beckmann products, whereas the single available hydroxyl group at the $14 \alpha$ position was either eliminated (13) or substituted with fluorine (14).

The reaction of calonysterone 2-acetate 20,22-acetonide (16) with DAST resulted in a highly complex, multi-component mixture of products that had been subjected to a multistep preparative HPLC separation. This led to the isolation of one single product, compound 17, in a very low yield. The subsequent structure elucidation of this compound revealed an unexpected cyclopropane ring closure between $\mathrm{C}-3$ and $\mathrm{C}-5$, providing a unique, five-membered A-ring steroid skeleton to the product. DAST is known to form a carbocation by water elimination. Our hypothesis is that this intermediate could react with the $\Delta^{5,6}$-olefin of the substrate, inducing ring closure and the subsequent rearrangement of the conjugated double bonds of rings $B$ and $C$. The stereoselectivity of the reaction should be due to the rigid steroid skeleton. To further elaborate this notion, cholesterol (18) was selected as a structurally related, commercially available model compound for a DAST-mediated transformation under the same synthetic conditions as before. This reaction selectively yielded 19. This compound showed ${ }^{1} \mathrm{H}$ (Fig. S50) and APT (Attached Proton Test, Fig. S52) spectra very similar to that of $\mathbf{1 8}$. Noticeable differences were identified 
only for the A-ring signals, mainly around C-3. The nearly $\sim 25 \mathrm{ppm}$ paramagnetic shift of $\delta \mathrm{C}-3$ at $92.8 \mathrm{~d} \mathrm{ppm}$ and its characteristic $\left({ }^{1} \mathrm{C}_{\mathrm{C}, \mathrm{F}}=174 \mathrm{~Hz}\right)$ signal splitting proved C-3 fluorination. To analyze the broad multiplet $\mathrm{H} \alpha-3$ signal at 4.39 ppm the $\mathrm{H}_{2}-4$ hydrogen atoms were decoupled, and thus the simplified multiplicity allowed reading of the couplings of $\mathrm{H \alpha}-3\left({ }^{2} J_{\mathrm{H}, \mathrm{F}}=51 \mathrm{~Hz} ; J_{2 \alpha, 3 \alpha}=4.8 \mathrm{~Hz}\right.$ and $\left.J_{2 \beta, 3 \alpha}=11.1 \mathrm{~Hz}\right)$. Due to the rather crowded feature of the ${ }^{1} \mathrm{H}$ spectrum, the ${ }^{1} \mathrm{H},{ }^{1} \mathrm{H}-\mathrm{COSY}$ (Fig. S51) could be used only for separated signals, but the selROE experiment (Fig. S51) on signal 4.39 ppm marked out the $\mathrm{H} \alpha-2$ and $\mathrm{H} \alpha-1$ signals (1.99 and $1.07 \mathrm{ppm}$, respectively). To overcome difficulties caused by the moderate resolution of the HSQC experiment (Fig. S53), band-selective HSQC method was used to unambiguously assign the neighboring signals in the ranges of 36-37 and 39-40 ppm. selROE experiment was used in combination with edited HSQC to elucidate stereochemistry of hydrogen atoms (Fig. S54), and the HMBC experiment (Fig. S55), especially correlations of hydrogens of 18, 19, 21, 26 and 27 methyl groups supported the assignments. Combination of all these experiments allowed a complete ${ }^{1} \mathrm{H}$ and ${ }^{13} \mathrm{C}$ assignment for compound 19. The result of this transformation is shown in Figure 3.

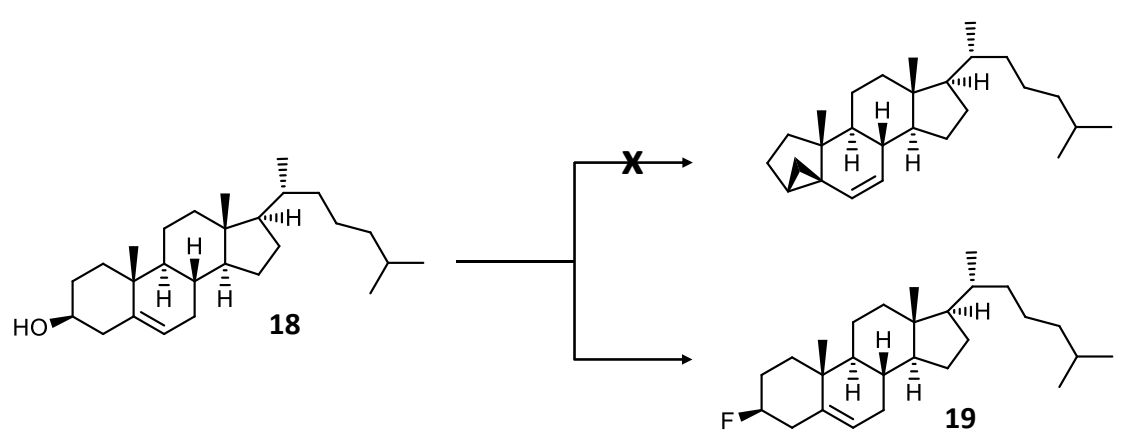

Figure 5. DAST-mediated fluorination of cholesterol (18). Reagents and conditions: DAST, anh. $\mathrm{CH}_{2} \mathrm{Cl}_{2},-84{ }^{\circ} \mathrm{C} \rightarrow \mathrm{room}$ temperature, $70 \mathrm{~min}$.

In contrast to the case of calonysterone 2-acetate 20,22-acetonide (17), the reaction of cholesterol (18) with DAST selectively yielded the corresponding 3-fluorine analogue (19) of the substrate, and no traces of the sought cyclopropane ring-closed derivative was observed in the product mixture. Nevertheless, the retained $\beta$-orientation of the fluorine substituent confirms the $S_{\mathrm{N}} 1$ reaction mechanism and therefore the involvement of a carbocation intermediate. This supports the mechanism proposed for the ring closure to form compound 17, while a more extended conjugation in the B-ring, such as the o-quinol dienone moiety of calonysterone, may be a prerequisite for the rearrangement to a cyclopropane ring.

\subsection{Biology}

2.3.1 Cytotoxicity, anti-proliferative and ABCB1 inhibitory activities

Selected compounds were tested on two mouse lymphoma cell lines: L5178Y, and its transfected multi-drug resistant counterpart, LT5178YMDR that expresses a major human MDR efflux transporter, ABCB1. Results are summarized in Table 3.

Table 3. Cytotoxicity and antiproliferative activity of compounds 5-7, 10, 11, 13,14 and 17 on mouse T-cell lymphoma cells, and functional inhibition of the ABCB1 transporter. For the ABCB1 inhibition, positive control: $20 \mathrm{nM}$ of tariquidar (87.5\% inhibition), negative control: $2 \%$ DMSO (0.2\% inhibition).

\begin{tabular}{ccc}
\hline $\begin{array}{c}\text { Cytotoxicity } \\
\left(\mathrm{IC} \mathrm{C}_{50} \pm \mathrm{SD}[\mu \mathrm{M}]\right)\end{array}$ & $\begin{array}{c}\text { Antiproliferative effect } \\
\left(\mathrm{IC} \mathrm{C}_{50} \mathrm{SD}[\mu \mathrm{M}]\right)\end{array}$ & ABCB1 Inhibition (\%)
\end{tabular}




\begin{tabular}{ccccccc} 
& L5178Y & L5178YMDR & L5178Y & L5178YMDR & $2 \mu M$ & $20 \mu M$ \\
\hline $\mathbf{3}$ & $>100$ & $>100$ & $75.5 \pm 4.1$ & $>100$ & -0.03 & -0.35 \\
$\mathbf{5}$ & $>100$ & $>100$ & $56.5 \pm 6.0$ & $80.2 \pm 2.1$ & 0.20 & -0.41 \\
$\mathbf{6}$ & $91.1 \pm 6.8$ & $>100$ & $31.2 \pm 3.9$ & $54.1 \pm 2.3$ & -0.38 & 0.13 \\
$\mathbf{7}$ & $38.6 \pm 1.6$ & $57.5 \pm 6.3$ & $15.2 \pm 1.9$ & $20.0 \pm 2.4$ & -0.24 & 0.29 \\
$\mathbf{9}$ & $>100$ & $>100$ & $49.2 \pm 3.4$ & $85.2 \pm 5.1$ & -0.40 & -0.42 \\
$\mathbf{1 0}$ & $72.9 \pm 5.6$ & $83.0 \pm 5$ & $27.7 \pm 0.6$ & $42.3 \pm 1.5$ & -0.38 & -0.16 \\
$\mathbf{1 1}$ & $91.9 \pm 9.3$ & $81.9 \pm 2.9$ & $31.8 \pm 2.1$ & $55.7 \pm 5.9$ & -0.57 & -0.51 \\
$\mathbf{1 3}$ & $>100$ & $>100$ & $4.6 \pm 0.8$ & $4.8 \pm 0.6$ & 0.09 & -0.01 \\
$\mathbf{1 4}$ & $>100$ & $>100$ & $71.6 \pm 1.5$ & $65.9 \pm 2.1$ & 0.20 & -0.12 \\
$\mathbf{1 6}$ & $63.0 \pm 4.4$ & $78.7 \pm 6.7$ & $50.3 \pm 0.2$ & $40.0 \pm 3.4$ & 0.71 & 15.7 \\
$\mathbf{1 7}$ & $27.2 \pm 1$ & $35.9 \pm 0.6$ & $20.3 \pm 1$ & $14.3 \pm 0.5$ & 1.08 & 45.5 \\
Doxorubicin & $0.30 \pm 0.10$ & $8.1 \pm 2.8$ & $0.014 \pm 0.002$ & $0.71 \pm 0.2$ & - & - \\
\hline
\end{tabular}

The cell viability data indicated that all sidechain cleaved compounds exerted very weak cytotoxicity, while their cytostatic, antiproliferative activity was several times higher. This was particularly true for the 17- $N$-acetyl derivative $\mathbf{1 3}$ whose antiproliferative activity (IC 50 ca. $4.7 \mu \mathrm{M}$ ) was by a remarkable over 20 times stronger than its cytotoxicity $\left(\mathrm{IC}_{50}>\right.$ $100 \mu \mathrm{M})$. On the other hand, compound 17 that contains an intact sidechain was the most cytotoxic among the tested ecdysteroids, and its cytotoxicity was also in a similar dose range as its antiproliferative activity. Further, $\mathbf{1 7}$ was also the only compound that showed a significant, ca. 50\% direct ABCB1 inhibition. In line with our previous results [9], all sidechain shortened derivatives were inactive in this regard. Further structure activity relationships may also be concluded concerning the steroid core. When comparing the antiproliferative activities of compounds 10, 11, 13 and 14, it appears that a 17-N-acetyl group is favorable over the 17-acetyl, and that a $\Delta^{14,15}$ olefin is favorable over a $14 \alpha$-F group. Nevertheless, it is also clear that the effect of a 14-fluorine group on the antitumor activity of ecdysteroids depends on its chemical environment. In case of compounds 5, 6 and 7 that also contain a $\Delta^{6(9,11)}$ conjugated olefin, the antiproliferative activity increases in the $14-\mathrm{OH}<\Delta^{14,15}<14-\mathrm{F}$ order. This is well in agreement with our previous findings on the fluorination products of 20-hydroxyecdysone 2,3;20,22-diacetonide [7].

\subsubsection{Combination assays}

Compounds 7, 10, 11, 13, and 14 had sufficient individual antiproliferative properties for their assessment of chemo-sensitizing activity. This was carried out as an antiproliferative assay on L5178YMDR cells in combination with doxorubicin, arranged according to the checkerboard microplate method [23]. Results are shown in Table 4. 
Table 4. Chemo-sensitizing activity of compounds 7, 10, 11, 13, 14 on the L5178Y $Y_{\text {MR }}$ cell line towards doxorubicin at 50, 75 and $90 \%$ of growth inhibition (ED50, ED75 and ED90, respectively). CI: combination index; $\mathrm{Cl}_{\text {avg: }}$ weighted average $\mathrm{CI}_{\text {value; }} \mathrm{CI}_{\text {avg }}=\left(\mathrm{CI}_{50}+\right.$ $\left.2 \mathrm{CI}_{75}+3 \mathrm{CI}_{90}\right) / 6 . \mathrm{CI}<1, \mathrm{CI}=1$, and $\mathrm{CI}>1$ represent synergism, additivity, and antagonism, respectively. Dm, $\mathrm{m}$, and $\mathrm{r}$ represent antilog of the $\mathrm{x}$-intercept, slope, and linear correlation coefficient of the median-effect plot, respectively.

\begin{tabular}{ccccccccc}
\hline & $\begin{array}{c}\text { Drug ra- } \\
\text { tio }\end{array}$ & ED50 & ED75 & ED90 & Dm & $\mathrm{m}$ & $\mathrm{r}$ & CIavg \\
\hline \multirow{3}{*}{7} & $11.6: 1$ & 0.98 & 0.76 & 0.59 & 4.05 & 2.18 & 0.940 & 0.71 \\
& $23.1: 1$ & 1.16 & 1.26 & 1.37 & 7.83 & 1.32 & 0.971 & 1.30 \\
& $46.4: 1$ & 1.17 & 0.84 & 0.60 & 11.56 & 2.64 & 0.974 & 0.78 \\
\hline \multirow{3}{*}{$\mathbf{1 0}$} & $23.2: 1$ & 0.75 & 0.50 & 0.33 & 6.50 & 2.20 & 0.988 & 0.46 \\
& $46.4: 1$ & 0.87 & 0.51 & 0.30 & 10.99 & 2.76 & 0.983 & 0.46 \\
& $92.8: 1$ & 0.86 & 0.55 & 0.35 & 14.02 & 2.14 & 0.999 & 0.50 \\
& $185.6: 1$ & 1.02 & 0.61 & 0.36 & 19.47 & 2.37 & 0.989 & 0.55 \\
\hline \multirow{4}{*}{$\mathbf{1 1}$} & $23.2: 1$ & 0.78 & 0.56 & 0.41 & 7.00 & 2.43 & 0.964 & 0.52 \\
& $46.4: 1$ & 0.81 & 0.55 & 0.39 & 11.66 & 3.07 & 0.996 & 0.51 \\
& $92.8: 1$ & 0.77 & 0.53 & 0.38 & 15.83 & 3.42 & 0.991 & 0.49 \\
& $185.6: 1$ & 0.93 & 0.66 & 0.48 & 24.06 & 3.51 & 0.991 & 0.61 \\
& $371.2: 1$ & 0.95 & 0.72 & 0.55 & 28.63 & 3.27 & 0.968 & 0.67 \\
\hline \multirow{3}{*}{$\mathbf{1 3}$} & $23.2: 1$ & 0.64 & 0.55 & 0.49 & 8.17 & 2.65 & 0.992 & 0.53 \\
& $46.4: 1$ & 0.67 & 0.51 & 0.39 & 14.17 & 4.18 & 0.963 & 0.48 \\
& $92.8: 1$ & 0.55 & 0.51 & 0.47 & 17.54 & 2.60 & 0.966 & 0.50 \\
& $185.6: 1$ & 0.71 & 0.68 & 0.65 & 29.89 & 2.54 & 0.997 & 0.67 \\
\hline
\end{tabular}

Most of the compounds showed nearly additive to mild synergistic effects with doxorubicin. The only exception was the $17-\mathrm{N}$-acetyl derivative (13) that showed a relevant synergism with doxorubicin already at $50 \%$ inhibition. This, taken together with the potent cytostatic effect of compound 13, makes it a valuable candidate for further studies toward a chemosensitizer for combination therapy with the cytotoxic drug doxorubicin.

\section{Materials and Methods}

\subsection{Synthesis and chromatographic purification}

Solvents and reagents were purchased from Sigma (Merck KGaA, Darmstadt, Germany), and were used without any further purification. The progress of the reactions was monitored by thin layer chromatography on Kieselgel $60 \mathrm{~F}_{254}$ silica plates purchased from Merck (Merck KGaA, Darmstadt, Germany), and characteristic spots of compounds were examined under UV illumination at 254 and $366 \mathrm{~nm}$. Chromatographic purification of the semi-synthesized steroid derivatives was carried out in one or two steps, depending on the complexity of their product mixtures (see Table 5). For flash chromatography, a CombiFlash ${ }^{\circledR}$ Rf+ Lumen instrument (TELEDYNE Isco, Lincoln, NE, USA) was used that was equipped with ELS and diode array detectors. The crude product mixtures were separated on RediSep NP-silica flash columns (TELEDYNE Isco, Lincoln, NE, USA) purchased from commercial source. Purity analysis of products was performed via HPLC on normal- or reverse phase $5 \mu \mathrm{m}, 250 \times 4.6 \mathrm{~mm}, 100 \AA$, Phenomenex columns (Phenomenex Inc., Torrance, CA, USA) at $1 \mathrm{~mL} / \mathrm{min}$. flow rate, while using a dual pump (PU-2080) Jasco HPLC instrument (Jasco International Co. Ltd., Hachioji, Tokyo, Japan) that was equipped with an MD-2010 Plus PDA detector to collect data in a range of 210-400 nm. Preparative HPLC 
separations were carried out on an Armen Spot Prep II integrated HPLC purification system (Gilson, Middleton, WI, USA) with dual-wavelength detection applied.

\subsection{Preparation of ecdysteroid derivatives}

\subsubsection{Natural ecdysteroids isolated from plants or semi-synthesized before}

Ajugasterone C (1) was isolated during our previous phytochemical work [24]. Calonysterone 2-acetate (15) was isolated from a fraction of a commercial extract of Cyanotis arachnoidea C.B. Clarke (Shaanxi KingSci Biotechnology Co., Ltd., Xi'an, People's Republic of China) during the current study and is reported here as a new ecdysteroid. We have recently reported the purification process in detail. Briefly, calonysterone 2-acetate was obtained after the following fractionation steps: percolation with methanol, column chromatography on silica (eluted with dichloromethane - methanol / 95:5, v/v), column chromatography on Lichroprep RP C18 (eluted with $20 \%$ aqueous acetonitrile), and column chromatography on silica $60 \mathrm{GF}_{254}$. (eluted with $n$-hexane - ethyl acetate / 6:5, v/v). For ${ }^{1} \mathrm{H}$ and ${ }^{13} \mathrm{C}$ NMR chemical shifts of compound 15 see Table 2.

Poststerone was previously prepared by semi-synthesis from 20-hydroxyecdysone isolated from the same extract of C. arachnoidea [9].

3.2.2 Preparation of sidechain cleaved ajugasterone $C$ derivative (2)

An aliquot of $2 \mathrm{~g}$ of ajugasterone C (1) $(4.16 \mathrm{mmol})$ was dissolved in $160 \mathrm{ml}$ of methanol and 1.2 equiv. ( $2.15 \mathrm{~g}$; $4.99 \mathrm{mmol}$ ) of PIDA was added to the solution. The reaction mixture was stirred at room temperature for 60 minutes and subsequently neutralized by $5 \%$ aq. $\mathrm{NaHCO}_{3}$-solution. After evaporation under reduced pressure, the product's dry residue was redissolved in methanol, and silica gel ( $\sim 10 \mathrm{~g})$ was added to the solution. Following this, the solvent was evaporated to prepare the sample for dry loading flash chromatographic separation (see Table 5) to obtain $11 \alpha$-hydroxypoststerone (2) (1.11 g, $70.2 \%)$.

\subsubsection{General procedure for the preparation of ecdysteroid acetonides 3, 9, 16}

Compounds 2, 8, 15 were each dissolved in acetone in $1 \mathrm{~g} / 100 \mathrm{ml}$ concentration. To these solutions, $1 \mathrm{~g}$ of phosphomolybdic acid for each gram of starting material was added. The mixtures were sonicated at room temperature for 30 minutes. Then, the reaction mixtures were neutralized with $10 \%$ aq. $\mathrm{NaHCO}_{3}$-solution, which was followed by the evaporation of acetone under reduced pressure on a rotary evaporator. Compounds were extracted from their aqueous residue with $3 \times 50 \mathrm{ml}$ of dichloromethane, and the combined organic fractions were dried over $\mathrm{Na}_{2} \mathrm{SO}_{4}$. After filtration, the products' solutions were evaporated to dryness on a rotary evaporator. Compounds 3, 9, 16 were obtained in their pure form after dry loading flash chromatographic separation (see Table 5 ), in yields of $59.8 \%, 55.8 \%$ and $84.6 \%$, respectively.

\subsubsection{Preparation of poststerone 2,3-acetonide 20-oxime (12)}

An aliquot of $240 \mathrm{mg}$ of hydroxylamine hydrochloride $(3.47 \mathrm{mmol})$ was dissolved in ethanol, and under stirring, $195 \mathrm{mg}$ of potassium hydroxide $(3.47 \mathrm{mmol})$ was added to the solution. Following this, $930 \mathrm{mg}$ of poststerone 2,3-acetonide (9) $(2.31 \mathrm{mmol})$ was added to the resulting mixture. The reaction mixture was stirred at room temperature for 24 hours. Subsequently, the reaction solution was evaporated to dryness on a rotary evaporator, $50 \mathrm{ml}$ of water was added to the dry residue, and extraction was performed with 3 x $50 \mathrm{ml}$ of dichloromethane. The collected organic fractions were combined, dried over $\mathrm{Na}_{2} \mathrm{SO}_{4}$, filtered, and evaporated to dryness on a rotary evaporator. Subsequently, the dry residue was subjected to dry loading flash chromatographic purification (see Table 5), which afforded the desired 20-oxime product (12) in a yield of $82 \%(791 \mathrm{mg}) .{ }^{1} \mathrm{H}$ and ${ }^{13} \mathrm{C}$ NMR chemical shifts of compound 12 were in perfect agreement with our previously published data [15].

3.2.5 General procedure for the DAST-catalyzed transformation of ecdysteroids 
Compounds 3, 9, 12, 16, and 18 were each dissolved in anhydrous dichloromethane in a concentration of $10 \mathrm{mg} / \mathrm{ml}$ in a round-bottom flask. The solutions were cooled down to $-84^{\circ} \mathrm{C}$ in an ethyl-acetate containing liquid nitrogen-cooled bath, and under stirring, 1.5 equiv. of diethylaminosulfur trifluoride (DAST) was added to them dropwise. As the reaction progressed, the mixtures were let warm up to room temperature. After 70 minutes of stirring, the reactions were neutralized using $5 \%$ aq. $\mathrm{NaHCO}_{3}$-solution, and after water dilution, the compounds were extracted from their mixture with $3 \times 50 \mathrm{ml}$ of dichloromethane. The collected organic fractions were dried over $\mathrm{Na}_{2} \mathrm{SO}_{4}$, filtered, and subsequently evaporated under reduced pressure on a rotary evaporator. The purification procedures and yields of the obtained compounds $4,5,6,710,11,13,14,17,19$ are detailed in Table 5.

Table 5. HPLC and flash hromatographic methods used for the purification of the compounds. X g silica: "RediSep" flash chromatographic columns (TELEDYNE Isco, Lincoln, NE, USA). The following HPLC columns were used (each purchased from Phenomenex Inc., Torrance, CA, USA). “XB-C18”: Kinetex ${ }^{\circledast}, 5$ m, XB-C18, $100 \AA ̊ 2,250$ x 21.2 mm; “biphenyl”: Kinetex ${ }^{\circledR}, 5 \mu \mathrm{m}$,

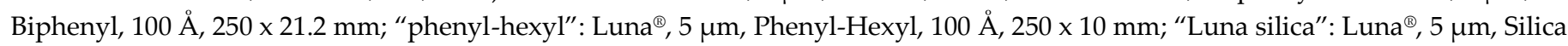
(2) $100 \AA 250 \times 21.2 \mathrm{~mm}$. Yields refer to the isolated yield\%. Chromatographic purification steps are given in v/v solvent ratios.

\begin{tabular}{|c|c|c|c|c|}
\hline compound (yield) & column & flow rate & elution & detection \\
\hline $2(70.2 \%)$ & $24 \mathrm{~g}$ silica & $35 \mathrm{ml} / \mathrm{min}$ & $\begin{array}{c}\mathrm{CH}_{2} \mathrm{Cl}_{2}: \mathrm{CH}_{3} \mathrm{OH}(\mathrm{A}: \mathrm{B}) \\
12 \% \mathrm{~B}(40 \mathrm{~min})\end{array}$ & $254 \mathrm{~nm}$ \\
\hline $3(78.9 \%)$ & $24 \mathrm{~g}$ silica & $35 \mathrm{ml} / \mathrm{min}$ & $\begin{array}{c}\mathrm{CH}_{2} \mathrm{Cl}_{2} \text { : ethyl-acetate (A:B) } \\
2 \rightarrow 4 \% \text { B (60 min) }\end{array}$ & $254 \mathrm{~nm}$ \\
\hline $4(6.1 \%)$ & \multirow{4}{*}{$\begin{array}{l}\text { (1) biphenyl } \\
\text { (2) phenyl-hexyl }\end{array}$} & \multirow{4}{*}{$15 \mathrm{ml} / \mathrm{min}$} & \multirow{4}{*}{$\begin{array}{l}\text { (1) water : } \mathrm{CH}_{3} \mathrm{CN}(\mathrm{A}: \mathrm{B}) \\
26 \% \text { B } 40 \mathrm{~min}-40 \% \mathrm{~B} 40-60 \mathrm{~min} \\
\text { (2) water : } \mathrm{CH}_{3} \mathrm{CN}(\mathrm{A}: \mathrm{B}) \\
44 \% \mathrm{~B} \text { (30 min) }\end{array}$} & \multirow{4}{*}{$254 \mathrm{~nm}$} \\
\hline $5(19.4 \%)$ & & & & \\
\hline $6(9.4 \%)$ & & & & \\
\hline $7(3.4 \%)$ & & & & \\
\hline $9(55.8 \%)$ & $80 \mathrm{~g}$ silica & $60 \mathrm{ml} / \mathrm{min}$ & $\begin{array}{c}\mathrm{CH}_{2} \mathrm{Cl}_{2}: \mathrm{CH}_{3} \mathrm{OH}(\mathrm{A}: \mathrm{B}) \\
0 \rightarrow 3 \% \mathrm{~B}(60 \mathrm{~min})\end{array}$ & $254 \mathrm{~nm}$ \\
\hline $10(20.3 \%)$ & \multirow{2}{*}{ XB-C18 } & \multirow{2}{*}{$15 \mathrm{ml} / \mathrm{min}$} & water : $\mathrm{CH}_{3} \mathrm{CN}(\mathrm{A}: \mathrm{B})$ & \multirow{2}{*}{$\begin{array}{l}254 \mathrm{~nm} \\
300 \mathrm{~nm}\end{array}$} \\
\hline $11(12.0 \%)$ & & & $42 \% \mathrm{~B}(40 \mathrm{~min})$ & \\
\hline $12(82.0 \%)$ & $24 \mathrm{~g}$ silica & $35 \mathrm{ml} / \mathrm{min}$ & $\begin{array}{c}\mathrm{CH}_{2} \mathrm{Cl}_{2}: \mathrm{CH}_{3} \mathrm{OH}(\mathrm{A}: \mathrm{B}) \\
0 \rightarrow 5 \% \mathrm{~B}(70 \mathrm{~min})\end{array}$ & $254 \mathrm{~nm}$ \\
\hline $13(16.6 \%)$ & \multirow{2}{*}{$\begin{array}{l}\text { (1) XB-C18 } \\
\text { (2) Luna silica }\end{array}$} & \multirow{2}{*}{$15 \mathrm{ml} / \mathrm{min}$} & $\begin{array}{c}\text { (1) water: } \mathrm{CH}_{3} \mathrm{CN}(\mathrm{A}: \mathrm{B}) \\
35 \% \mathrm{~B}(40 \mathrm{~min})\end{array}$ & \multirow{2}{*}{$\begin{array}{l}245 \mathrm{~nm} \\
300 \mathrm{~nm}\end{array}$} \\
\hline $14(6.1 \%)$ & & & $\begin{array}{l}\text { (2) cyclohexane : (2-propanol : wa- } \\
\text { ter } 97: 3)(\mathrm{A}: \mathrm{B}) \\
17 \% \mathrm{~B}(40 \mathrm{~min})\end{array}$ & \\
\hline $16(84.6 \%)$ & $80 \mathrm{~g}$ silica & $60 \mathrm{ml} / \mathrm{min}$ & $\begin{array}{c}n \text {-hexane : (acetone : 2-propanol } \\
8: 2)(\mathrm{A}: \mathrm{B}) \\
10 \rightarrow 15 \% \mathrm{~B}(60 \mathrm{~min})\end{array}$ & $254 \mathrm{~nm}$ \\
\hline $17(6.4 \%)$ & $\begin{array}{l}\text { (1) Luna silica } \\
\text { (2) XB-C18 }\end{array}$ & $15 \mathrm{ml} / \mathrm{min}$ & $\begin{array}{l}\text { (1) cyclohexane : 2-propanol (A:B) } \\
3 \% \text { B (40 min) } \\
\text { (2) water : } \mathrm{CH}_{3} \mathrm{CN}(\mathrm{A}: \mathrm{B}) \\
63 \% \mathrm{~B}(40 \mathrm{~min})\end{array}$ & $\begin{array}{l}254 \mathrm{~nm} \\
366 \mathrm{~nm}\end{array}$ \\
\hline $19(43.9 \%)$ & $40 \mathrm{~g}$ silica & $40 \mathrm{ml} / \mathrm{min}$ & $100 \%$-hexane $(60 \mathrm{~min})$ & $210 \mathrm{~nm}$ \\
\hline
\end{tabular}

\subsection{Structure elucidation}

${ }^{1} \mathrm{H}(600$ and $500 \mathrm{MHz})$ and ${ }^{13} \mathrm{C}(150$ and $125 \mathrm{MHz}) \mathrm{NMR}$ spectra were recorded at room temperature on Bruker Avance III NMR spectrometers equipped with Prodigy and cryoprobe heads, using $\mathrm{CDCl}_{3}$, DMSO- $\mathrm{d}_{6}$ or $\mathrm{MeOH}-\mathrm{d}_{4}$ as solvents. Chemical shifts are given on a $\delta$ scale and referenced to the solvents $\left(\mathrm{CDCl}_{3} \delta \mathrm{H}=7.27\right.$ and $\delta \mathrm{C}=77.0 \mathrm{ppm}$; 
DMSO-d $\mathrm{d}_{6} \delta \mathrm{H}=2.50$ and $\delta \mathrm{C}=39.5 \mathrm{ppm}$; and $\mathrm{CH}_{3} \mathrm{OH}-\mathrm{d}_{4} \delta \mathrm{H}=3.31$ and $\delta \mathrm{C}=49.1 \mathrm{ppm}$ ). Coupling constant $(J)$ values are expressed in Hz. Aliquots of approximately $2-5 \mathrm{mg}$ samples were dissolved in $0.1 \mathrm{~mL}$ of solvent and transferred to $2.5 \mathrm{~mm}$ Bruker MATCH NMR sample tubes or $0.6 \mathrm{~mL}$ to $5 \mathrm{~mm}$ NMR sample tubes. Pulse programs of all experiments $\left({ }^{1} \mathrm{H},{ }^{13} \mathrm{C}\right.$, DEPTQ, APT, sel-TOCSY, sel-ROE ( $\left.\tau_{\text {mix: }} 300 \mathrm{~ms}\right)$, sel-NOE, edited gs-HSQC, band-selective-gs-HSQC and gs-HMBC) were taken from the Bruker software library. ${ }^{1} \mathrm{H}$ and ${ }^{13} \mathrm{C}$ NMR data for the new compounds are presented in Tables 1 and 2. Characteristic NMR spectra of these compounds, along with their stereostructures, ${ }^{1} \mathrm{H}$ and ${ }^{13} \mathrm{C}$ assignments, characteristic HMBC correlations and steric proximities are presented in Figures S1-S55, Supporting Information. High-resolution mass spectra were recorded on a Q Exactive Plus Hybrid Quadrupole-Orbitrap mass spectrometer (Thermo Fisher Scientific, Waltham, MA, USA), and they are shown in Figures S56-S64.

\subsection{Cell lines}

L5178Y mouse T-cell lymphoma cells (ECACC Cat. No. 87111908) were obtained from FDA, Silver Spring, MD, USA. These were transfected with $\mathrm{pHa}$ MDR1/A retrovirus

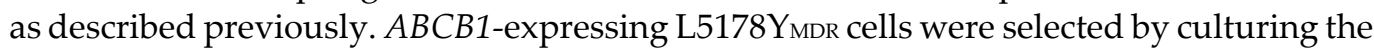
infected cells with colchicine. The cell lines were cultured in McCoy's 5A medium supplemented with 10\% heat inactivated horse serum, $200 \mathrm{mM}$ L-glutamine, and penicillinstreptomycin mixture in $100 \mathrm{U} / 1$ (L5178) or $10 \mathrm{mg} / \mathrm{l}$ (L5178MDR) concentration.

\subsection{Cell viability assay for determination of cytotoxicity and antiproliferative activity}

MTT assay was performed in 96-well flat-bottomed microtiter plates as described before. Briefly, a $10 \mathrm{mM}$ concentration stock solution in DMSO was prepared for each compound. These were diluted in $100 \mu \mathrm{L}$ of McCoy's 5A medium. Subsequently, a sum of $1 \times$ $10^{4}$ cells (cytotoxicity assay) or $6 \times 10^{3}$ cells (antiproliferative assay) in $100 \mu \mathrm{L}$ of medium were added to each well, except for the medium control wells. The culture plates were further incubated at $37^{\circ} \mathrm{C}$ for $24 \mathrm{~h}$ (cytotoxicity assay) or $72 \mathrm{~h}$ (antiproliferative assay); at the end of the incubation period, $20 \mu \mathrm{L}$ of MTT solution (from a $5 \mathrm{mg} / \mathrm{mL}$ stock) was added to each well. After incubation at $37^{\circ} \mathrm{C}$ for $4 \mathrm{~h}, 100 \mu \mathrm{L}$ of SDS solution $(10 \%$ in $0.01 \mathrm{M} \mathrm{HCI})$ was added to each well and the plates were further incubated at $37^{\circ} \mathrm{C}$ overnight. The cell growth was determined by measuring the optical density at $540 \mathrm{~nm}$ (ref. $630 \mathrm{~nm}$ ) with a Multiscan EX ELISA reader (Thermo Labsystems, Cheshire, WA, USA). IC 50 values were calculated by variable slope nonlinear regression using the $\log$ (inhibitor) vs. normalized response of GraphPad Prism 5.01 (GraphPad Software Inc, San Diego, CA, USA).

\subsection{ABCB1 inhibition assay}

ABCB1 inhibition was determined by the intracellular accumulation of rhodamin 123 as reported before [10]. Briefly, $2 \times 10^{6}$ cells/mL of L5178Y and L5178YMDR cell lines were re-suspended in serum-free McCoy's 5A medium and distributed in $0.5 \mathrm{~mL}$ aliquots into Eppendorf centrifuge tubes. The compounds were added at a final concentration of 2 or $20 \mu \mathrm{M}$ and the samples were incubated for $10 \mathrm{~min}$ at room temperature. Tariquidar was used as positive control and DMSO as negative control; for the latter, no activity was observed. Subsequently, $10 \mu \mathrm{L}(5.2 \mu \mathrm{M}$ final concentration) of the ABCB1 substrate fluorescent dye rhodamine 123 was added and the cells were incubated further for 20 min at 37 ${ }^{\circ} \mathrm{C}$, washed twice and re-suspended in $1 \mathrm{~mL}$ PBS for analysis. Fluorescence of the cell population was measured with a PartecCyFlow ${ }^{\circledR}$ flow cytometer (Partec, Münster, Germany). Mean fluorescence intensity percentage was calculated for the treated vs. untreated L5178Y YDR cells. Inhibition percentage for the treated cells was calculated from the corresponding values of the untreated L5178Y and L5178YMDR cells, representing 0\% and $100 \%$ inhibition, respectively.

\subsection{Combination assay}


The checkerboard microplate method was used to evaluate the compounds interaction with doxorubicin, as described before [10]. Briefly, doxorubicin ( $2 \mathrm{mg} / \mathrm{mL}$, Teva Pharmaceuticals, Budapest, Hungary) was serially diluted in the horizontal direction (100 $\mu \mathrm{L}$ per well), and the ecdysteroid was subsequently diluted in the vertical direction (50 $\mu \mathrm{L}$ per well). L5178Y $Y_{M D R}$ cells were re-suspended in culture medium and added to each test well in $50 \mu \mathrm{L}$ to contain $1 \times 10^{4}$ cells per well, and $50 \mu \mathrm{L}$ of medium was added to the medium control wells. The plates were incubated for $72 \mathrm{~h}$ at $37^{\circ} \mathrm{C}$ in a $\mathrm{CO}_{2}$ incubator and, at the end of the incubation period, the cell growth was determined by MTT assay as described above. Cell viability data were analyzed by the Calcusyn software using the Chou method [23], and drug interactions were expressed as combination index (CI) values, in which $0 \leq \mathrm{CI}<1, \mathrm{CI}=1$, and $\mathrm{CI}>1$ refer to synergism, additivity, and antagonism, respectively.

\section{Conclusions}

On the example of ecdysteroids, we demonstrated that DAST-mediated transformation of natural products containing several $\mathrm{OH}$ groups is a valuable tool for diversityoriented semi-synthesis of new bioactive compounds. Several unique ecdysteroid derivatives were obtained, and the DAST-mediated formation of a cyclopropane ring was described for the first time. Combinations of the different reactions that can be mediated by DAST manifested in the chemical complexity of the compounds obtained, and this allowed us to reveal valuable structure-activity relationships concerning their antitumor activity.

Altogether, the new ecdysteroids showed stronger antitumor properties than their parent compounds, and particularly compound 13 demonstrated a potent cytostatic activity against drug susceptible and multi-drug resistant cancer cell lines. Further, it showed synergism with doxorubicin on a Pgp expressing MDR cancer cell line without functional efflux pump inhibition.

Supplementary Materials: The following are available online at www.mdpi.com/xxx/s1, Figures S1-S55: Characteristic NMR spectra, stereostructures, ${ }^{1} \mathrm{H}$ and ${ }^{13} \mathrm{C}$ assignments, characteristic HMBC correlations and steric proximities of the new compounds, Figures S56-64: HRMS spectra of the new compounds.

Author Contributions: Conceptualization, A.H.; methodology, M.V., T.G., G.T. and A.H.; investigation, M.V., E.K., M.N., Z.K., R.B., T.G., and G.T.; data curation, G.T. and A.H.; writing-original draft preparation, E.K., M.V. and G.T.; writing-review and editing, A.H.; supervision, G.S and A.H.; funding acquisition, A.H. All authors have read and agreed to the published version of the manuscript.

Funding: This research was funded by the National Research, Development and Innovation Office, Hungary (NKFIH; K-134704) and the Economic Development and Innovation Operative Program GINOP-2.3.2-15-2016- 00012, with the support of the Szeged Scientists Academy under the sponsorship of the Hungarian Ministry of Innovation and Technology (FEIF/646-4/2021-ITM_SZERZ).

Conflicts of Interest: The authors declare no conflict of interest.

\section{References}

1. Gouverneur, V.; Seppelt, K. Introduction: Fluorine Chemistry. Chemical Reviews 2015, 115, 563-565, doi:10.1021/cr500686k.

2. Meanwell, N.A. Fluorine and Fluorinated Motifs in the Design and Application of Bioisosteres for Drug Design. Journal of Medicinal Chemistry 2018, 61, 5822-5880, doi:10.1021/acs.jmedchem.7b01788.

3. Inoue, M.; Sumii, Y.; Shibata, N. Contribution of Organofluorine Compounds to Pharmaceuticals. ACS Omega 2020, 5, 10633-10640, doi:10.1021/acsomega.0c00830.

4. Kaźmierczak, M.; Bilska-Markowska, M. Diethylaminosulfur Trifluoride (DAST) Mediated Transformations Leading to Valuable Building Blocks and Bioactive Compounds. European Journal of Organic Chemistry 2021, 2021, 5585-5604, doi:

10.1002/ejoc.202101027. 
5. Wang, Q.; Tang, X.Y.; Shi, M. Metal-Free Cross-Coupling of Arylboronic Acids and Derivatives with DAST-Type Reagents for Direct Access to Diverse Aromatic Sulfinamides and Sulfonamides. Angew Chem Int Ed Engl 2016, 55, 10811-10815, doi:10.1002/anie.201605066.

6. Jiang, H.; Shen, H.; Zhu, S.; Wang, B.; Yang, Y.; Nong, Z.; Yi, M.; Tang, S.; Gui, Q.-W. Diethylaminosulfur Trifluoride: A Novel, Low-Cost, Stable Double Thiolation Reagent for Imidazo[1,2- $\alpha$ ]pyridines. ACS Omega 2021, 6, 26273-26281, doi:10.1021/acsomega.1c03291.

7. Csábi, J.; Martins, A.; Sinka, I.; Csorba, A.; Molnár, J.; Zupkó, I.; Tóth, G.; Tillekeratne, L.M.V.; Hunyadi, A. Synthesis and in vitro evaluation of the antitumor potential and chemo-sensitizing activity of fluorinated ecdysteroid derivatives. MedChemComm 2016, 7, 2282-2289, doi:10.1039/c6md00431h.

8. Balázs, A.; Hunyadi, A.; Csábi, J.; Tillekeratne, L.M.V.; Martins, A.; Tóth, G. New cyclic 2,3-sulfite ester derivatives of poststerone-Discriminating diastereomers and probing spatial proximities by NMR and DFT calculations. Magnetic Resonance in Chemistry 2017, 55, 1102-1107, doi: 10.1002/mrc.4641.

9. Hunyadi, A.; Csábi, J.; Martins, A.; Molnár, J.; Balázs, A.; Tóth, G. Backstabbing P-gp: Side-Chain Cleaved Ecdysteroid 2,3Dioxolanes Hyper-Sensitize MDR Cancer Cells to Doxorubicin without Efflux Inhibition. Molecules 2017, $22,199$.

10. Martins, A.; Tóth, N.; Ványolós, A.; Béni, Z.; Zupkó, I.; Molnár, J.; Báthori, M.; Hunyadi, A. Significant Activity of Ecdysteroids on the Resistance to Doxorubicin in Mammalian Cancer Cells Expressing the Human ABCB1 Transporter. Journal of Medicinal Chemistry 2012, 55, 5034-5043, doi:10.1021/jm300424n.

11. Vágvölgyi, M.; Martins, A.; Kulmány, Á.; Zupkó, I.; Gáti, T.; Simon, A.; Tóth, G.; Hunyadi, A. Nitrogen-containing ecdysteroid derivatives vs. multi-drug resistance in cancer: Preparation and antitumor activity of oximes, oxime ethers and a lactam. European journal of medicinal chemistry 2018, 144, 730-739, doi:10.1016/j.ejmech.2017.12.032.

12. Savchenko, R.G.; Nové, M.; Spengler, G.; Hunyadi, A.; Parfenova, L.V. In vitro adjuvant antitumor activity of various classes of semi-synthetic poststerone derivatives. Bioorg Chem 2021, 106, 104485, doi:10.1016/j.bioorg.2020.104485.

13. Bolotin, D.S.; Bokach, N.A.; Demakova, M.Y.; Kukushkin, V.Y. Metal-Involving Synthesis and Reactions of Oximes. Chem Rev 2017, 117, 13039-13122, doi:10.1021/acs.chemrev.7b00264.

14. Mirjafary, Z.; Abdoli, M.; Saeidian, H.; Boroon, S.; Kakanejadifard, A. Oxime ethers as versatile precursors in organic synthesis: a review. RSC Advances 2015, 5, 79361-79384, doi:10.1039/c5ra15299b.

15. Bogdán, D.; Haessner, R.; Vágvölgyi, M.; Passarella, D.; Hunyadi, A.; Gáti, T.; Tóth, G. Stereochemistry and complete 1H and 13C NMR signal assignment of C-20-oxime derivatives of posterone 2,3-acetonide in solution state. Magnetic Resonance in Chemistry 2018, 56, 859-866, doi:10.1002/mrc.4750.

16. Alamri, M.A.; Altharawi, A.; Alabbas, A.B.; Alossaimi, M.A.; Alqahtani, S.M. Structure-based virtual screening and molecular dynamics of phytochemicals derived from Saudi medicinal plants to identify potential COVID-19 therapeutics. Arabian Journal of Chemistry 2020, 13, 7224-7234, doi:10.1016/j.arabjc.2020.08.004.

17. Ley, S.; Baumann, M.; Baxendale, I. The Use of Diethylaminosulfur Trifluoride (DAST) for Fluorination in a ContinuousFlow Microreactor. Synlett 2008, 2008, 2111-2114, doi:10.1055/s-2008-1078026.

18. Duddeck, H.; Dietrich, W.; Tóth, G. Structure Elucidation by Modern NMR; 1998; 10.1007/978-3-642-88310-1.

19. Pretsch, E.; Tóth, G.; Munk, E.M.; Badertscher, M. Computer-Aided Structure Elucidation; Wiley-VCH: 2002.

20. Csábi, J.; Hsieh, T.-J.; Hasanpour, F.; Martins, A.; Kele, Z.; Gáti, T.; Simon, A.; Tóth, G.; Hunyadi, A. Oxidized Metabolites of 20-Hydroxyecdysone and Their Activity on Skeletal Muscle Cells: Preparation of a Pair of Desmotropes with Opposite Bioactivities. Journal of Natural Products 2015, 78, 2339-2345, doi:10.1021/acs.jnatprod.5b00249.

21. Li, H.; Qin, J.; Yang, Z.; Guan, X.; Zhang, L.; Liao, P.; Li, X. DAST-promoted Beckmann rearrangement/intramolecular cyclization of acyclic ketoximes: access to 2-oxazolines, benzimidazoles and benzoxazoles. Chem Commun (Camb) 2015, 51, 8637-8639, doi:10.1039/c5cc02155c. 
22. Kim, D.; Lim, H.N. Synthesis of Acyl Fluorides via DAST-Mediated Fluorinative C-C Bond Cleavage of Activated Ketones. Org Lett 2020, 22, 7465-7469, doi:10.1021/acs.orglett.0c02603.

23. Chou, T.C. Theoretical basis, experimental design, and computerized simulation of synergism and antagonism in drug combination studies. Pharmacol Rev 2006, 58, 621-681, doi:10.1124/pr.58.3.10.

24. Hunyadi, A.; Herke, I.; Lengyel, K.; Báthori, M.; Kele, Z.; Simon, A.; Tóth, G.; Szendrei, K. Ecdysteroid-containing food supplements from Cyanotis arachnoidea on the European market: evidence for spinach product counterfeiting. Sci Rep 2016, 6, 37322, doi:10.1038/srep37322. 